\title{
Update on invasive fungal infections in the Middle Eastern and North African region
}

\author{
Marwan Osman ${ }^{1} \cdot$ Aisha Al Bikai $^{1} \cdot$ Rayane Rafei $^{1} \cdot$ Hassan Mallat $^{1} \cdot$ Fouad Dabboussi $^{1} \cdot$ Monzer Hamze $^{1}$ (i)
}

Received: 12 December 2019 / Accepted: 22 June 2020 / Published online: 5 July 2020

(C) Sociedade Brasileira de Microbiologia 2020

\begin{abstract}
In the recent years, the epidemiology of invasive fungal infections (IFIs) has changed worldwide. This is remarkably noticed with the significant increase in high-risk populations. Although surveillance of such infections is essential, data in the Middle Eastern and North African (MENA) region remain scarce. In this paper, we reviewed the existing data on the epidemiology of different IFIs in the MENA region. Epidemiological surveillance is crucial to guide optimal healthcare practices. This study can help to guide appropriate interventions and to implement antimicrobial stewardship and infection prevention and control programs in countries.
\end{abstract}

Keywords Invasive fungal infections · Invasive candidiasis · Invasive aspergillosis $\cdot$ Pneumocystis pneumonia $\cdot$ Cryptococcal meningitis $\cdot$ Mucormycosis $\cdot$ Histoplasmosis

\section{Introduction}

Invasive fungal infections (IFIs) have turned out to be a major public health concern along with the expansion of at-risk populations besides the lack of universal implementation of definitive diagnostics [1]. Numerous major risk factors for IFIs have been described including surgery, total parenteral nutrition, fungal colonization, renal replacement therapy, hemodialysis, mechanical ventilation, diabetes mellitus (DM), broadspectrum antibiotics use, red blood cells transfusion, antifungal medication, central venous catheter, and peripheral catheter use [2]. In fact, IFIs can be divided into two categories: endemic mycoses like histoplasmosis and opportunistic mycoses like invasive candidiasis (IC), invasive aspergillosis (IA), cryptococcal meningitis (CM), Pneumocystis jirovecii pneumonia (PJP) [3].

Marwan Osman and Aisha Al Bikai contributed equally to this work.

Editorial Responsibility: Carlos Pelleschi Taborda

Monzer Hamze

mhamze@monzerhamze.com

1 Laboratoire Microbiologie Santé et Environnement (LMSE), Doctoral School of Science and Technology, Faculty of Public Health, Lebanese University, Tripoli, Lebanon
In liver transplant recipients, Pneumocystis is the underlying pathogen in $7 \%$ of all pneumonia cases [4]. The European Organization for Research and Treatment of Cancer (EORTC) in a cohort study has indicated that fungemia ranged from $0.15 \%$ in patients with solid tumors to $1.55 \%$ in hematopoietic stem cell transplantation recipients. It occurred predominantly due to Candida spp. infections (90\%), where C. albicans (46.5\%), and non-albicans Candida (NAC) (53.5\%) were found in patients [5]. IFIs are an important cause of morbidity and mortality among high-risk groups including solid organ transplantation (SOT) recipients and hematological malignancy patients. For instance, mortality rates were the highest for IA $(67-82 \%)$ as well as cerebral forms of mucormycosis $(73.5 \%)$ [6].

Even though there are limited choices of antifungals, treating patients with confirmed fungal disease with effective antifungal agents is crucial to reduce morbidity and mortality. Also, several investigations described a significant link between early reliable diagnosis and treatment of IFIs and improved outcomes of patients at risk [7]. The diagnostic includes traditional methods like culture, histopathology, and imaging expertise and newer antigen- and PCR-based diagnostic assays [8].

In this review, we focus on the epidemiology, burden and incidences of IFIs in the Middle Eastern and North African (MENA) region among high-risk groups, to support infectious disease specialists and healthcare workers in this geographic 
area and assist the provision of optimal care for patients susceptible to IFIs.

\section{Epidemiology of invasive fungal infections in the MENA region}

Since the increase of IFIs is strongly associated with the expanding immunosuppressed population and the increase in invasive diagnostics and treatment, an urgent need for surveillance of the changing trends in incidences is required. The knowledge of the current situation allows the assessment of the burden of such infections in the region. Thus, PubMed, Science Direct, Scopus, and Google Scholar databases search was done for epidemiological studies of IFIs from tertiary care hospitals published in the last decade. We used a combination of the keywords for paper retrieving including the following: "invasive fungal infections," "invasive fungal disease," "invasive candidiasis," "candidaemia," "invasive aspergillosis," "pneumocystis pneumonia," "mucormycosis," "histoplasmosis," in addition to a MENA country. Indexed original articles and case reports in English and French of any design and sampling strategy were included. Despite the globally growing importance of invasive infections, especially among the high susceptible risk groups, the epidemiological assessment of the status of IFIs is underestimated in the MENA region. Indeed, only very few reports about the estimation of IFIs were found in this region in the last decade. In the next parts of this review, we will discuss the available data concerning IC, IA, CM, Pneumocystis pneumonia, mucormycosis, and histoplasmosis in the region.

\section{Invasive candidiasis}

Candida infections accounts for approximately 70 to $90 \%$ of total IFIs [9]. Global estimates indicated that $\sim 750,000$ cases of IC occur annually [10]. Candidemia (Candida bloodstream infection) is the most common clinical presentation of IC and occurs mainly in hospitalized patients with an ascribable mortality of $15-35 \%$ for adults and $10-15 \%$ for neonates [11]. Only five species contribute to almost $92 \%$ of cases of candidemia: Candida albicans, Candida glabrata, Candida tropicalis, Candida parapsilosis, and Candida krusei. C. albicans is the most common etiological agent worldwide [11]. However, an upward trend in the incidence of NAC in IC cases was witnessed worldwide, which may be correlated with an increasing use of triazoles, mainly fluconazole [12]. Furthermore, a recent emerging multi-drug resistant Candida species, Candida auris, has been reported to cause healthcareassociated fungal infections [13]. In comparison with Candida species, several characteristics make the opportunistic $C$. auris unique in the field of clinical mycology such as his ability to colonize inert surfaces, capacity to cause nosocomial invasive infections, resistance to some commonly used chlorine-based disinfectants, and non-susceptibility to any or all of the systemic antifungal drugs available at this time $[14,15]$.

Epidemiological studies assessing the status of IC, including candidemia, are underestimated in the developing world, counting MENA countries (Table 1). Several studies have estimated the incidence rates of candidemia in MENA countries. Candidemia incidence rate was estimated to be the highest in Qatar, with an estimated rate of $(15.4 / 100,000)$ [16] and the lowest in Iran $(0.34 / 100,000)$ [17] (Fig. 1). IC and other IFIs were compared with reported estimations in different countries at global level (Fig. 2).

As for the available epidemiological studies, only a few were found to assess the status of IC and candidemia. In Lebanon, only one study took place in the past 10 years. The study evaluating 2011-2012 data of three hospitals, with a mean of 2.2-2.5 co-morbid conditions per patient, has reported the incidence of IC to be 0.39 cases per 1000 hospital discharges [39]. In Jordan, an overall incidence rate of 0.48 episodes/1000 admissions was recorded in an academic tertiary hospital, with a 30-day mortality rate of $38.7 \%$ [40]. In Turkey, several studies have shown that nosocomial IC, including candidemia, ranged between 1.2/1000 and 5.6/1000 admissions [41-43]. The incidence of candidemia in ICUs ranged from 1.76 patients/1000 ICU admissions to 11.5 per 1000 neonatal ICU admissions among neonates [44, 45]. However, a prospective study in Iran indicated higher incidence rate of candidemia (15.2/1000 in neonatal ICU admissions), with a $42.5 \%$ mortality rate [46]. A systematic review and meta-analysis identified 55 cases of candidemia in Iran where the risk factors were surgery and burns (23.6\%), malignancies $(20 \%)$, use of broad-spectrum antibiotics $(18.2 \%)$, and diabetes $(7.3 \%)$ [47].

As for the Arabian Peninsula, it has been recorded in Saudi Arabia that IC rates ranged from $1.55-1.65$ cases per 1000 discharges to 26 cases per 1000 ICU admissions [39, 48, 49]. A retrospective study on IC among pediatric patients indicated a group of risk factors: prematurity in $37(28.7 \%)$ of patients, low birth weight $(32.6 \%)$, central venous catheter (45.7\%), malignancy (16.3\%), immunotherapy (15.5\%), and ventilator support (46.5\%) [50]. In 2002-2009, data indicated that malignancy was independently associated with the development of candidemia [51]. In Kuwait, candidemia rate has decreased to a 0.15 cases/1000 in 2016 compared to 0.24 cases/1000 patient-days in 2014 [52]. In Qatar, 201 episodes of candidemia in 187 patients were identified in a singlecenter study [53].

In North Africa, candidemia in a pediatric ICU reached up to 3 per 1000 inpatient-days in Egypt [54]. A 15-year (19952009) retrospective analysis in the Sousse Region, Tunisia, had indicated an increase in the frequency of IC episodes, with an average of 24 episodes per year [55]. A previous study analyzing the data from 1995 to 2010 in the same region has shown an incidence of neonatal IC about 12.2 cases/1000 


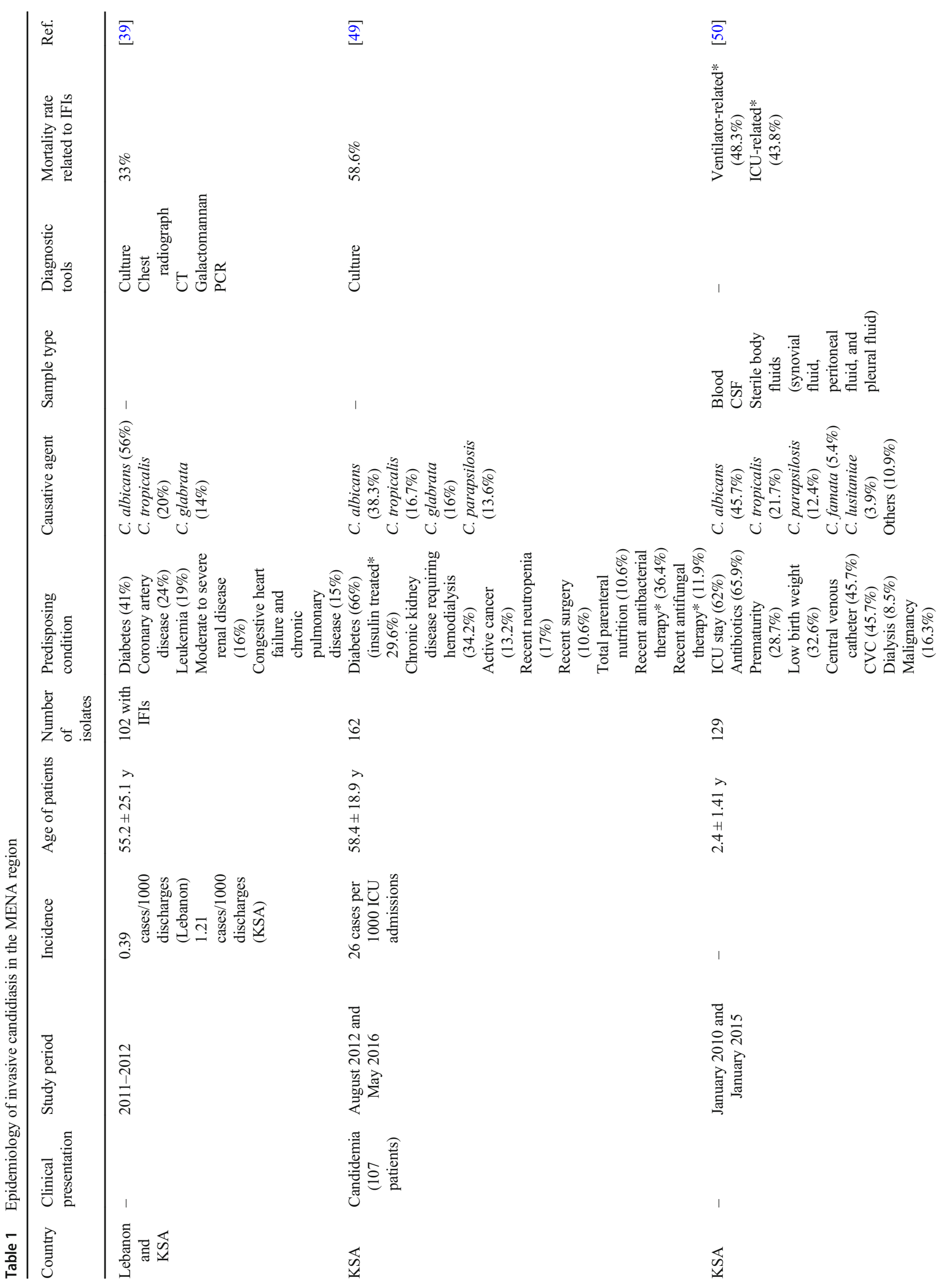




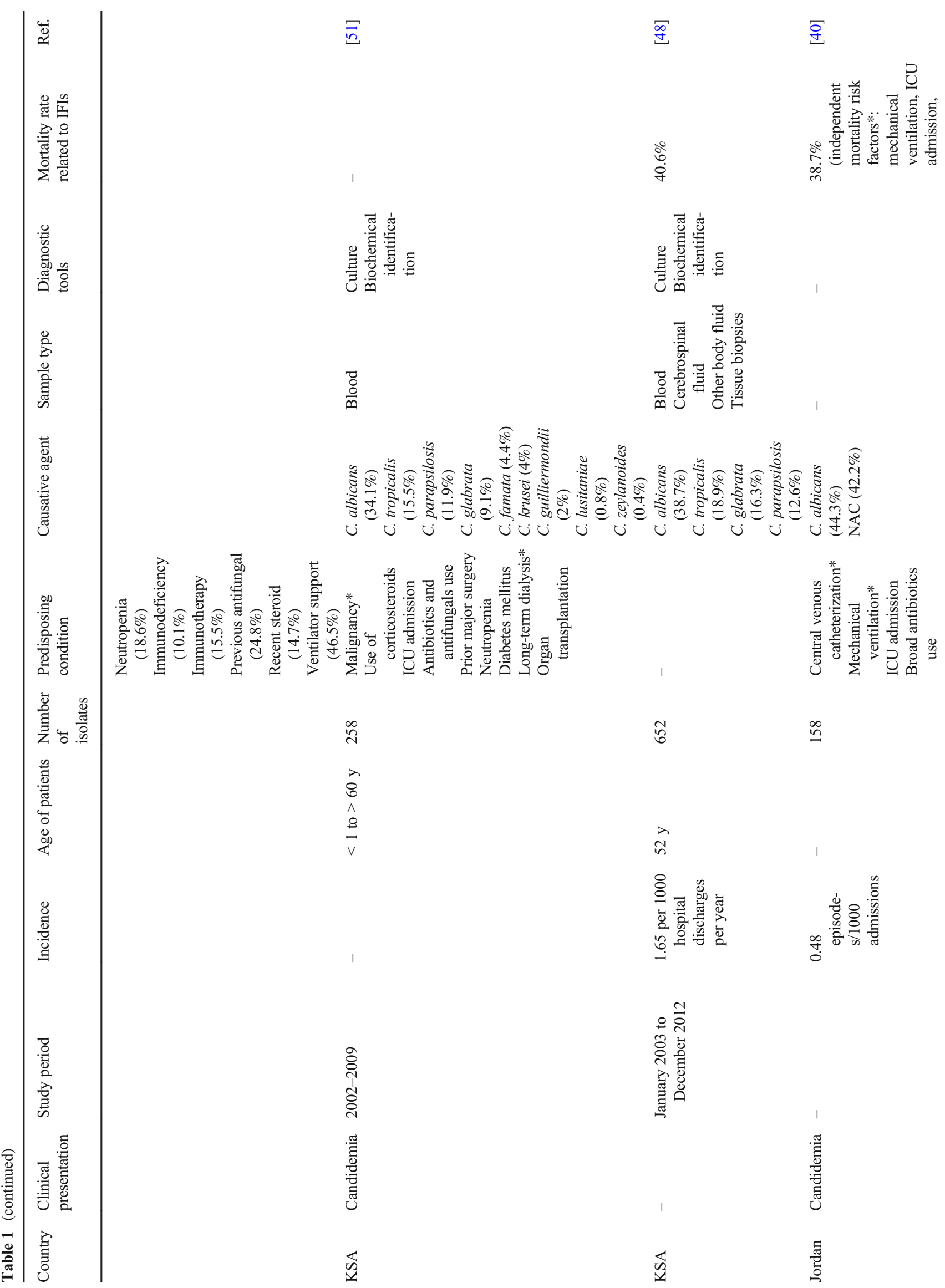




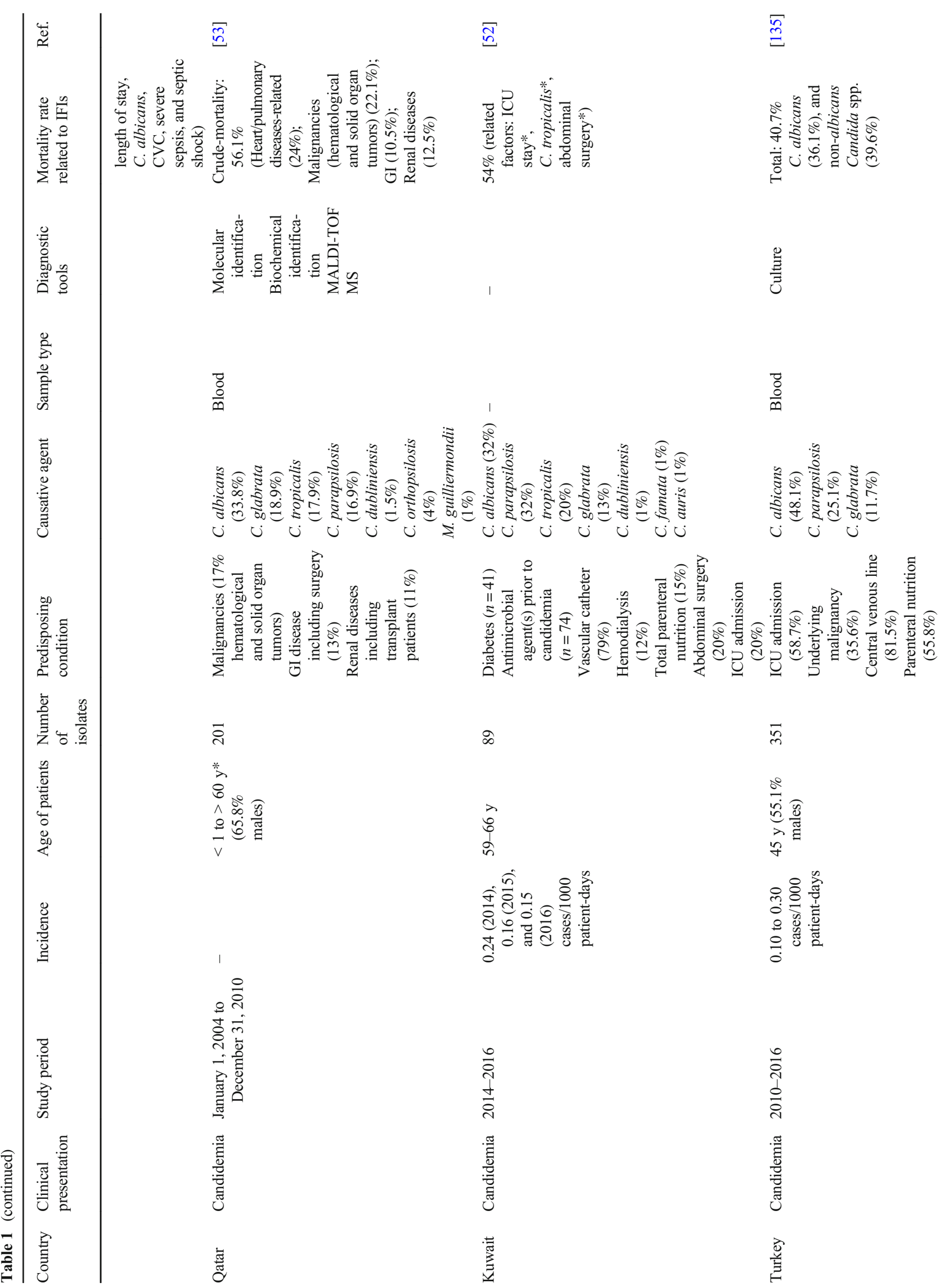




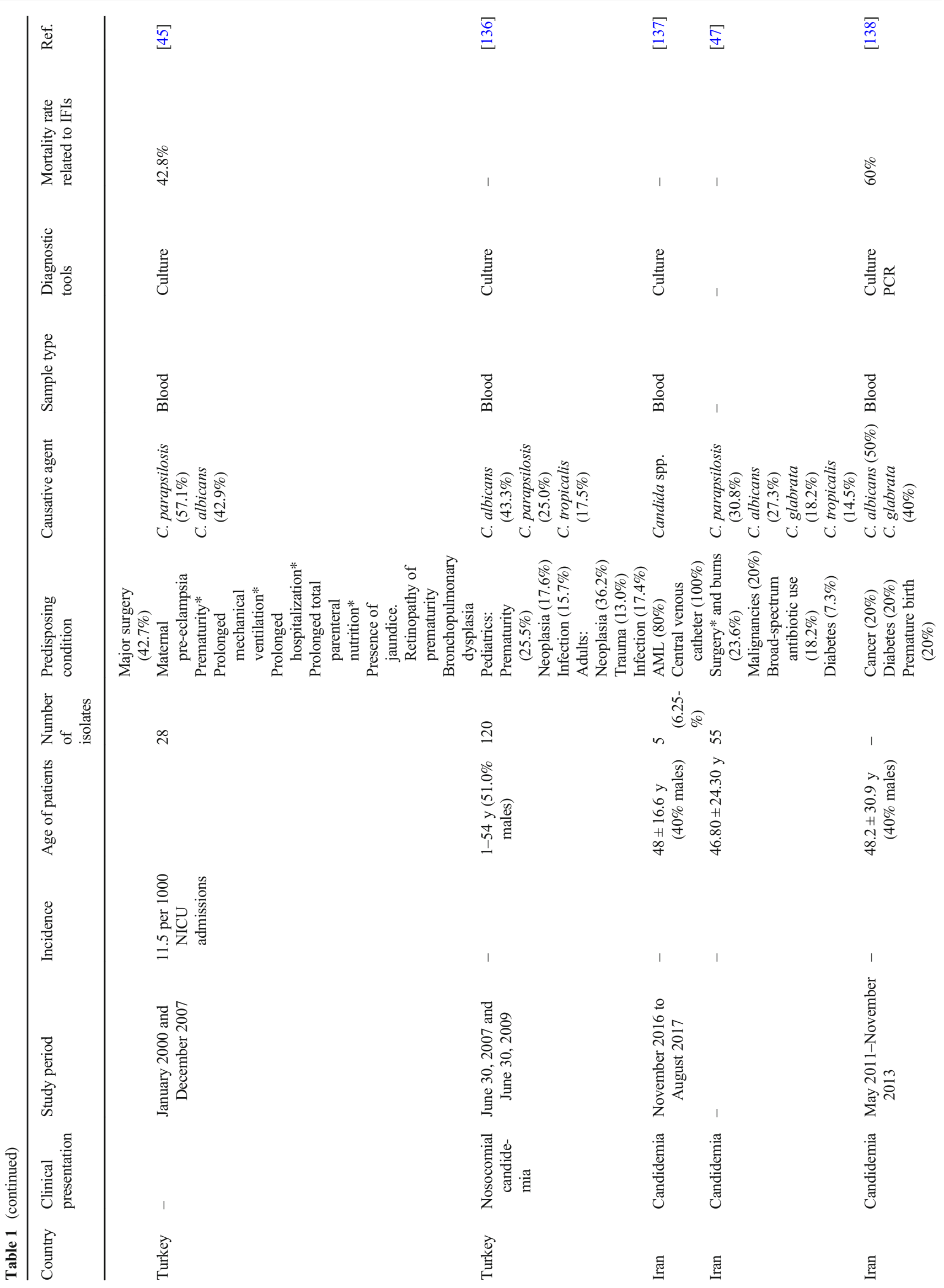




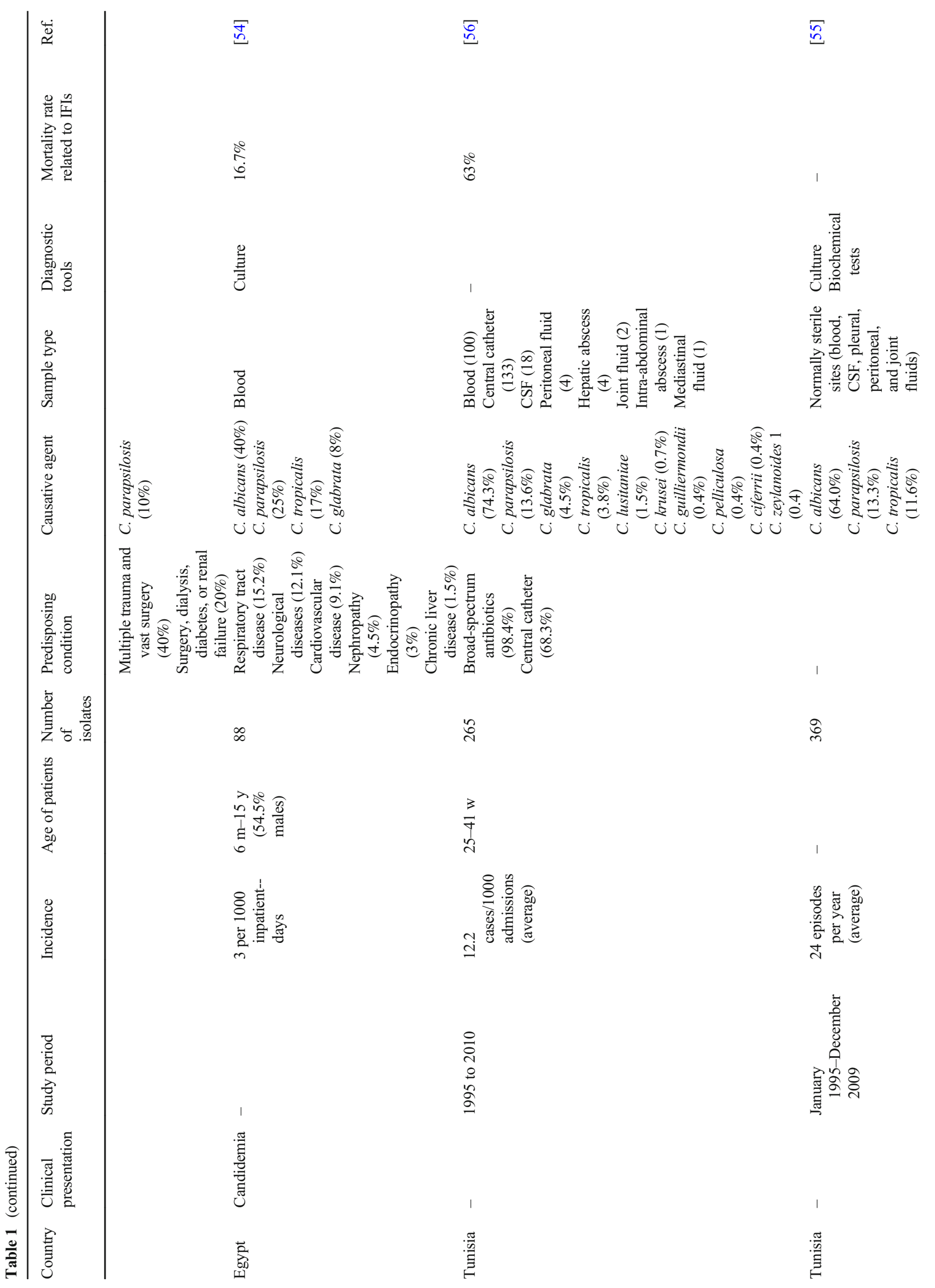




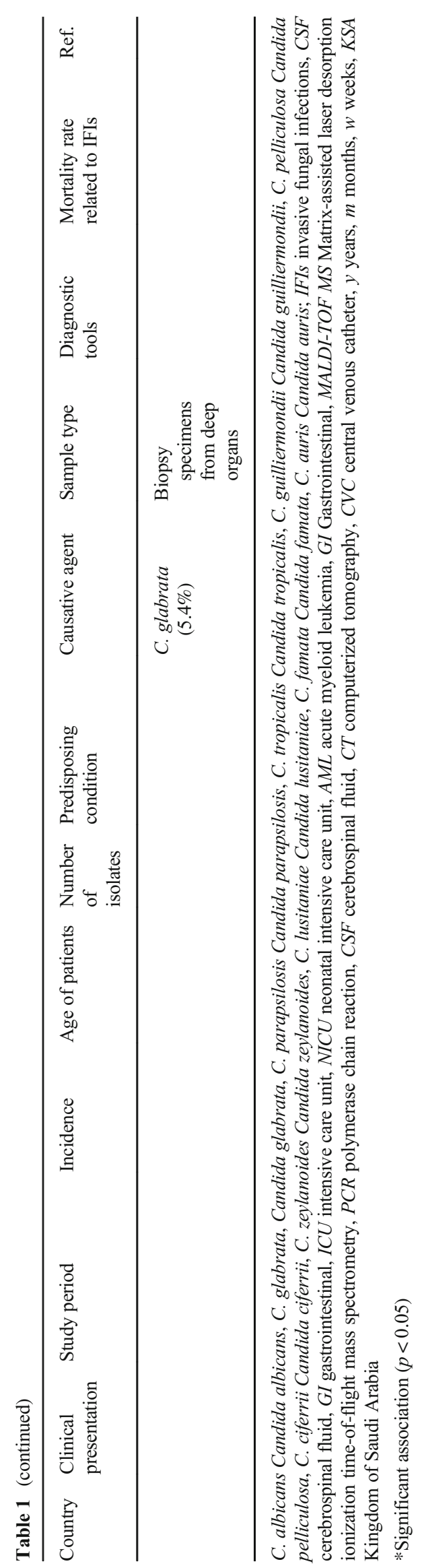




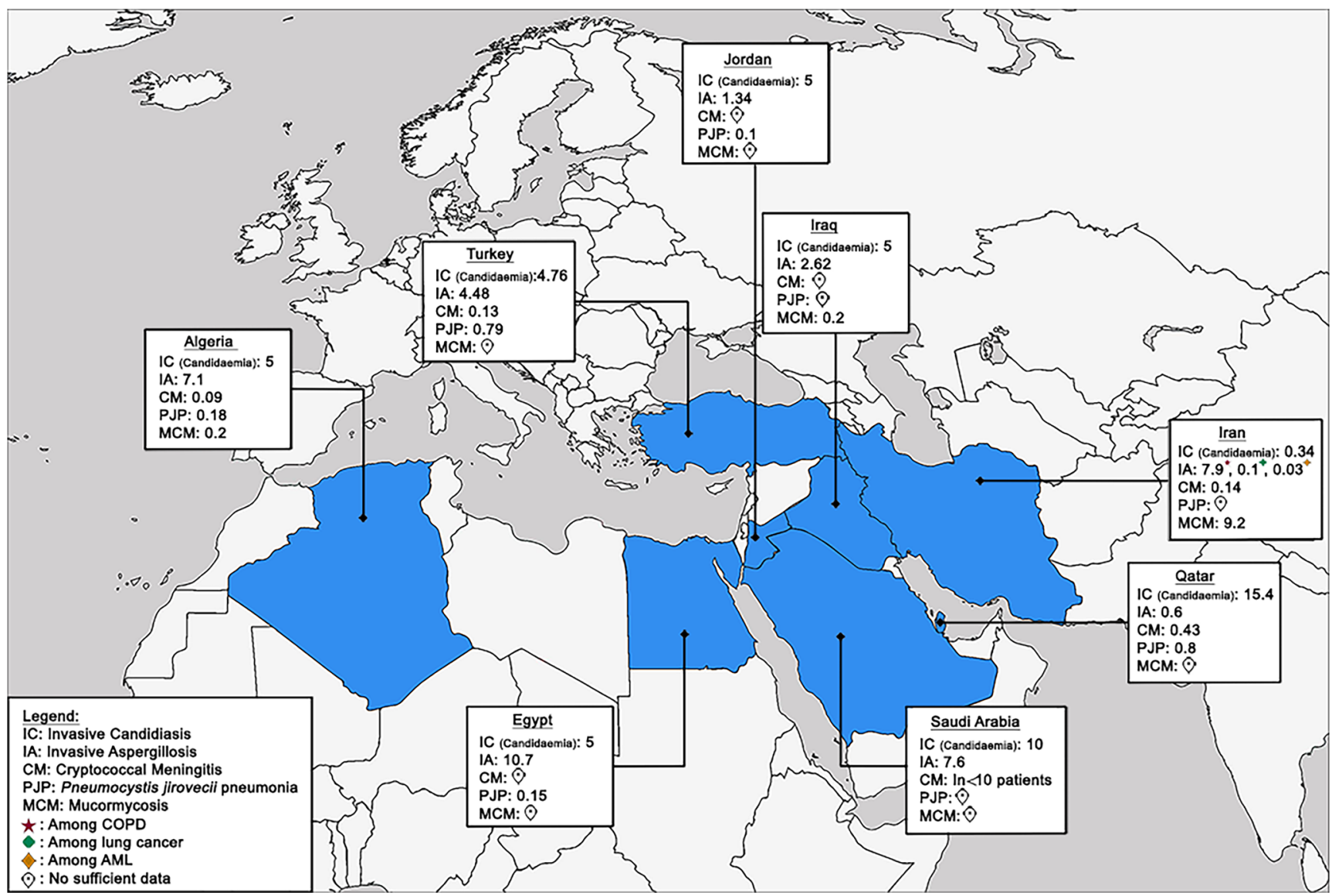

Fig. 1 Available estimates of the incidence rate (per 100,000 population) of invasive fungal infections in MENA countries [16-22]

admissions, with a fourfold decrease of incidence from 2007 to 2010 [56]. A retrospective study of IFI among renal transplant recipients from January 1995 to February 2013 reported only 2 cases of IC [57]. In Morocco, 8-month prospective surveillance from January to August 2011 conducted at the Casablanca University Hospital-pediatric hematology/ oncology unit - showed a healthcare-associated infections (HAIs) incidence of 28/1000 patient-days, where Candida accounted for $14 \%$ [58].

Some factors may have a probable role in the spread of IFIs among MENA countries. For instance, country socioeconomic status affects device-associated infection rates in developing countries and should be taken into account when comparing device-associated infections from one country to another [59]. In addition, the global share of the health research in the Eastern Mediterranean region is lower than the average percentage worldwide. The rise in academic health publications has been more common in only a few countries [60]. Furthermore, socio-political instabilities influence research output as well, such as in Egypt and Tunisia in the last few years. The concentration of biomedical and health research in the region's academic institutions is expected to help turn information into public health results, if more suitable conditions are given [60].
Based on data published in the last decade regarding IC causative agents, $C$. albicans was found to be the most prevalent in Iran (80\%) in a local study conducted in Tehran, followed by Turkey (48.3\%), Kuwait (37.22-47.2\%), and Qatar (30.2\%) [61, 62]. According to Ghazi et al. [62], an increase in NAC is being observed in the MENA region, especially in Saudi Arabia (48.1\%), Kuwait (52.8\%), Egypt (60\%), Qatar $(69.3 \%)$, and Tunisia $(\sim 76.1 \%)$. A decrease in the NAC incidence was observed in Turkey (from 52.43 to $44 \%$ ). With regard to the NAC distribution, C. tropicalis was prevalent in Saudi Arabia (15.5\%), and Tunisia (37.7\%), while C. glabrata predominated in Qatar (25.5\%), Turkey $(13.3 \%)$, and Iran (20\%) and C. parapsilosis in Kuwait (38.2\%) and Egypt (25\%) [62].

Concerning C. auris, it was associated with IC, mostly candidemia, in the United Arab Emirates, Kuwait, and Saudi Arabia [52, 63-68]. Surprisingly, while C. auris isolation in Kuwait has steadily increased over a study period and almost doubled in 2018 compared to 2017, a noteworthy finding of nearly sixfold increase was in bloodstream $C$. auris isolates in the same period [68]. Unfortunately, no reports of $C$. auris were found form other MENA countries. In fact, $C$. auris is closely related to the species of the $C$. haemulonii complex, leading to a misidentification with other Candida species such 


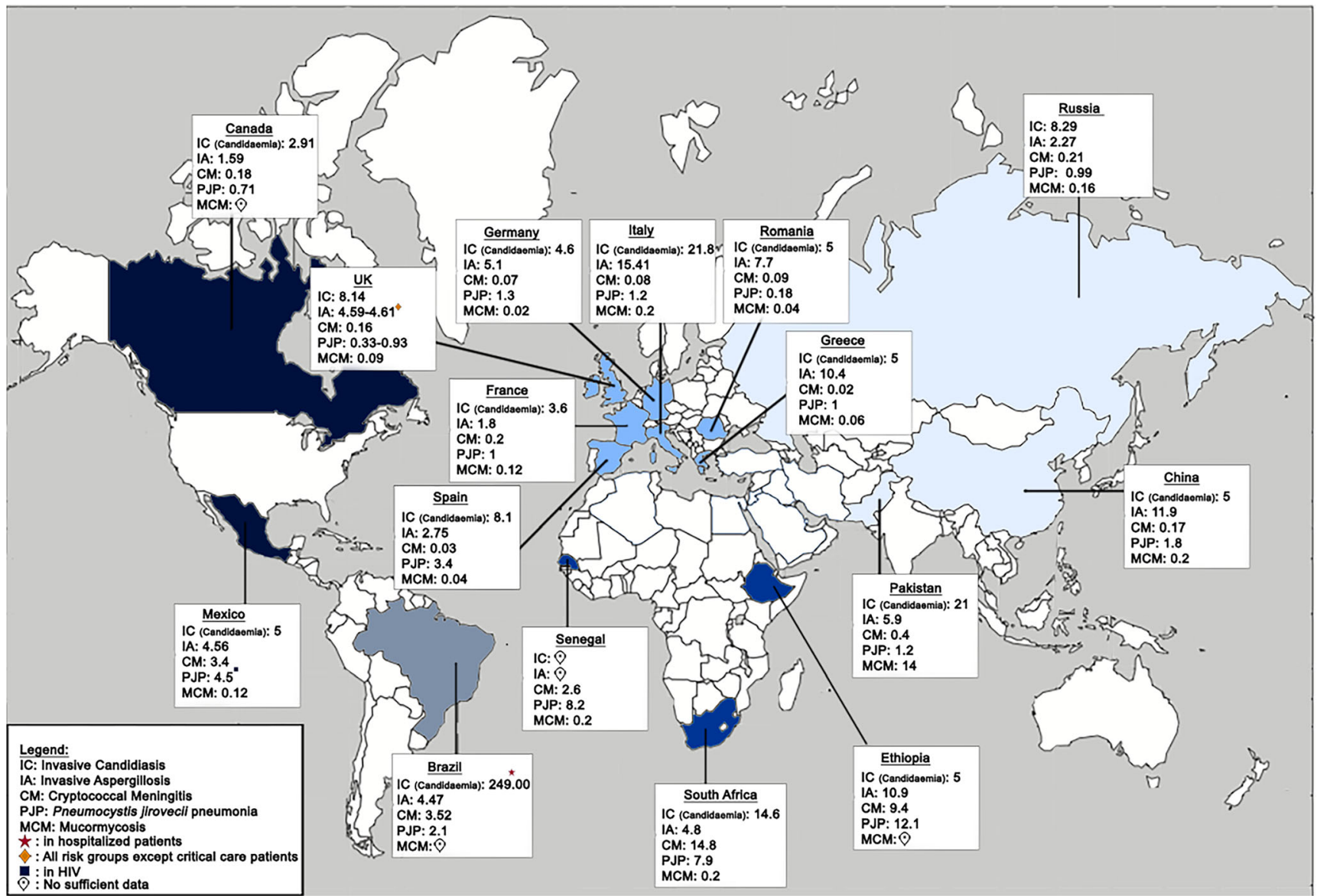

Fig. 2 Available estimates of the incidence rate (per 100,000 population) of invasive fungal infections in different countries around the world [23-38]

as C. haemulonii or C. famata $[69,70]$. Even though most of the region belong to the middle-income countries, the total mass of the publication of research is lower than its global proportion of population or income [60]. Most of the clinical microbiology laboratories in this geographic area are not yet supported with more advanced diagnostic tools that allow the extensive search for this agent, in contrary to the high-income countries, which reported and investigated to a certain extent the $C$. auris distribution. C. auris infection may be present in other countries as well, but its occurrence has not yet been investigated. Unfortunately, the insufficiency of conventional commercial systems to identify $C$. auris also leads to delayed intervention and treatment [70,71]. This will definitely cause a threat in the healthcare settings, since this fungal agent can contaminate and prevail in hospital environments, in addition to transfer between patients, and from health workers and abiotic surfaces of medical equipment to patients [72].

\section{Invasive aspergillosis}

IA is an opportunistic fungal infection affecting primarily the immunocompromised population: $70 \%$ of the total putative or proven IA happens in immunocompromised patients, in patients with chronic obstructive pulmonary disease (COPD), or patients with diabetes admitted to the ICUs [73]. It is estimated that $\sim 250,000$ cases occur annually [10]. IA is associated with elevated hospital mortality, extended duration of hospitalization, and high costs [74]. The causative agent Aspergillus spp. is a ubiquitous environmental mold that is found on organic matter, soil, and in the air as conidia [75]. Aspergillus fumigatus, Aspergillus flavus, Aspergillus niger, Aspergillus terreus, and Aspergillus versicolor are the most common causative species, where A. fumigatus is the commonest agent worldwide [76]. Despite the growing concern of aspergillosis, it is not thoroughly reported in the majority of MENA countries (Table 2).

IA burden estimates have been done for several MENA countries, and the highest estimated incidence rate in Egypt is $10.7 / 100,000$ [18], followed by Iran with $7.9 / 100,000$ among COPD cases, 0.1/100,000 among lung cancer cases, and 0.03/100,000 among acute myeloid leukemia cases [17]. In Saudi Arabia, incidence rate was 7.6/100,000 [19], followed by Algeria (7.1/100,000) [20], Turkey $(4.48 / 100,000)$ [21], Iraq $(2.62 / 100,000)$ [77], Jordan $(1.34 / 100,000)$ [22], and reached its lowest value $(0.6 / 100,000)$ in Qatar [16]. Moreover, the incidence of IA in Lebanon was estimated at 1.21 cases $/ 1000$ hospital discharges, higher than that found in Saudi Arabia with 0.4 cases/1000 hospital discharges [39]. In 


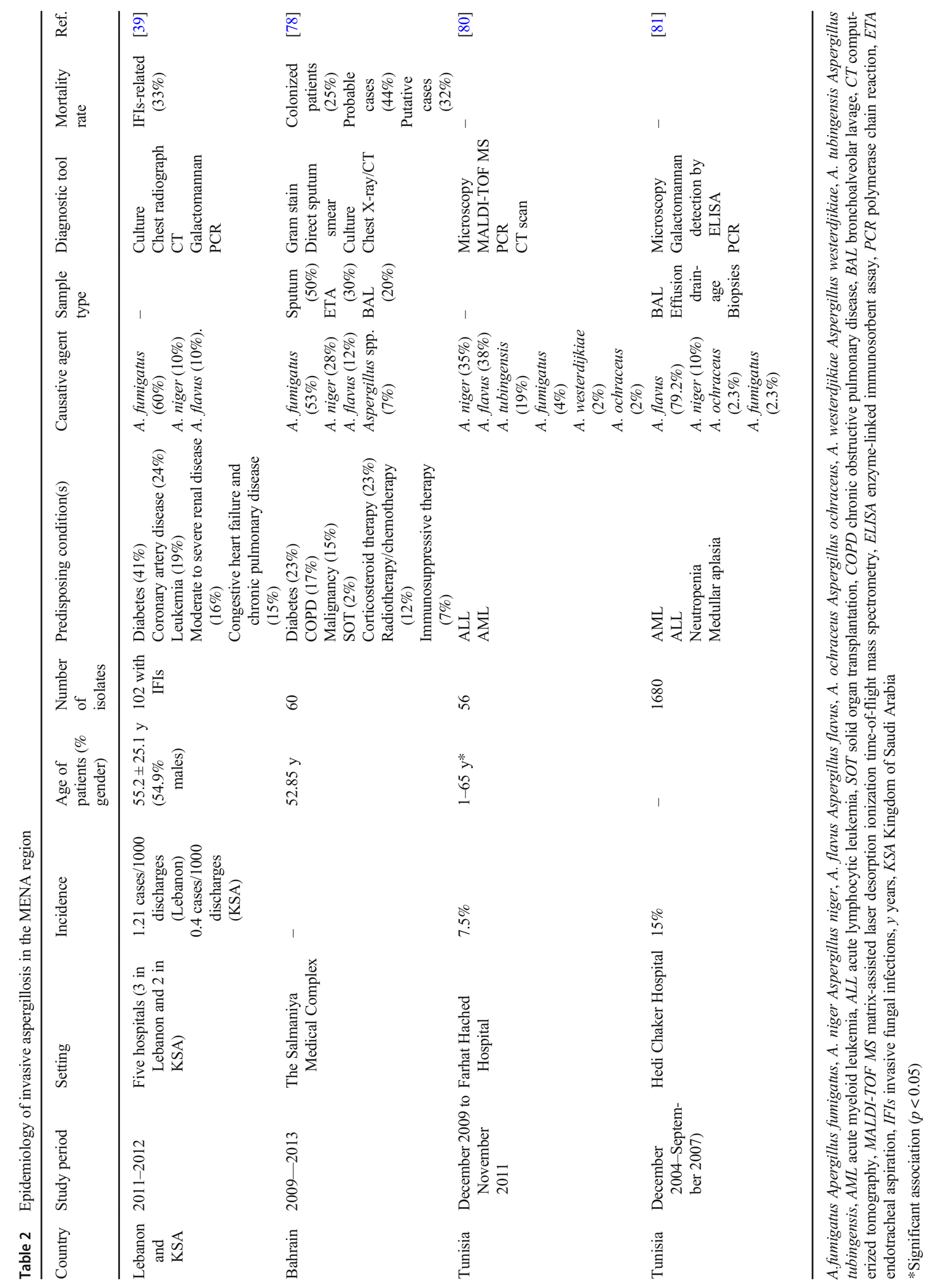


Bahrain, medical records during 2009-2013 of a tertiary care hospital of patients with positive Aspergillus cultures revealed $53.3 \%$ colonization and $46.7 \%$ presumed IA associated with $25 \%$ and $32 \%$ mortality respectively [78]. In Tunisia, the incidence of IA was 7.5-15\% among hematology patients [79-81]. A retrospective study of IFIs among renal transplant recipients at Habib Bourguiba Sfax university hospital from January 1995 to February 2013 reported 2 cases of aspergillosis [57]. Between 2002 and 2010, 29 cases of IA were reported in the Sousse Farhat Hached Hospital Hematology Unit, where acute myeloid leukemia (AML) was the most common disease $(65.5 \%)$ among the severely neutropenic patients [82].

Regarding species distribution, A. fumigatus predominated in IFIs of hospital discharges in both Lebanon and Saudi Arabia (60\%) [39] and was responsible for $53 \%$ of IA in Bahrain [78]. A. flavus was predominant in $75 \%$ of bronchoalveolar lavage (BAL) samples in Iran [83] and in $37.5 \%$ of sputum samples and $79.2 \%$ among clinical samples of hematology patients in Tunisia $[81,84]$.

\section{Cryptococcal meningitis}

Cryptococcus neoformans is the most common fungal agent that causing meningoencephalitis in the immunocompromised individuals worldwide [85], followed by Cryptococcus gatti [86]. C. neoformans is acquired through inhalation of spores or dried agent in the environment [87]. CM arises in $15 \%$ of AIDS-related mortality worldwide [88]. It is estimated that 223,100 incident cases occur globally, with an estimation of 181,100 annual deaths [88].

Considering $\mathrm{CM}$ as a rare fungal infection, it could not be estimated in Jordan [22], Iraq [77], and Egypt [18], in addition to being estimated to probably be affecting under 10 patients in Saudi Arabia [19]. In Qatar, CM had a low estimated incidence rate of 0.43 cases per 100,000 considering the low human immunodeficiency virus (HIV) rate in the country [16]. In Turkey, the estimated rate was 0.13 per 100,000 population with the prediction of 106 annual cases occurring among HIV patients [21]. Similarly, the incidence rate in Iran was estimated at 0.14 per 100,000 population [17]. In Algeria, a nearly negligible rate of 0.09 per 100,000 population was estimated [20].

Overall, few cases of CM were reported in the MENA region. A case was observed in a Turkish female who has undergone mastectomy and has had received chemotherapy following surgery [89]. In addition, a rare case of tenosynovitis caused by Cryptococcus luteolus was reported in a 68-yearold type 2 diabetic male [90]. Regarding Iran, a review article reported a case of CM caused by $C$. neoformans in HIVpositive Iranian female who died 4 days after antifungal therapy due to respiratory failure in Sari. The authors have also included 12 other reported cases of cryptococcosis due to Cryptococcus species between 1969 and 2014 [91].
Moreover, a study showed that the prevalence of cryptococcal infection in HIV-infected patients with a CD4 cell count of $<$ 100 cells $/ \mathrm{mm}^{3}$ was very low $(<3 \%)$ [92]. In fact, C. neoformans is highly prevalent in pigeon droppings in Iran, allowing its transmission to the environment and consequently to the patients at risk of developing CM [93, 94].

The first report of CM in the Arabian Peninsula was in Saudi Arabia in 1990, showing the occurrence of this disease in a child having systemic lupus erythematosus [95]. The only reported case from Kuwait was in 1995, considered the second in the Arabian Peninsula, in a 22-year-old man presented with confusional psychosis caused by $C$. neoformans serotype A [96]. However, in Oman, a study conducted between January 1999 and December 2008 showed that CM accounted for $22 \%$ of AIDS-defining opportunistic infections [97].

Regarding the North African region, $0.6 \%$ of CM cases were estimated among annually $\mathrm{HIV}$-infected patients in Egypt [18]. The first cases of CM were reported in two HIV-positive patients in Libya [98]. In Morocco, a study that was conducted from January 2005 to May 2015 showed that $\mathrm{CM}$ accounted for $20 \%$ of neurological disorders involved that was suggestive of HIV infection in $68.8 \%$ cases [99]. A 2016 cross-sectional study in Tunisia declared that CM was responsible for $11 \%$ out of $70.4 \%$ deaths associated with HIV [100]. Among renal transplant recipients between January 1995 to February 2013, 2 cases of cryptococcosis were reported [57].

\section{Pneumocystis pneumonia}

Pneumocystis spp., a ubiquitous yeast-like fungus that affects a wide variety of mammals, is a host strict agent where $P$. jirovecii infects primarily humans [101]. The main transmission route is through inhalation; however, some evidence suggests a direct-contact transmission route [102]. PJP is widely known as an HIV-positive-related opportunistic fungal infection. However, because of the extensive use of immunosuppressant drugs, non-HIV risk groups have emerged, particularly among cancer patients [103].

Concerning incidence rate estimates, it could not be estimated in both Iraq and Saudi Arabia due to the lack of data on PJP infections [19, 77]. In Qatar, the estimated rate was 0.8 per 100,000 population [16], followed by Turkey 0.79 per 100,000 [21], Algeria 0.18 per 100,000 [20], Egypt 0.15 per 100,000 [18], and Jordan 0.1 per 100,000 [22] (Table 3).

Case reports and epidemiological data on PJP were reported in few countries. A Lebanese report indicated a prevalence of $10.9 \%$ PJP cases among HIV patients [104]. In Turkey, the prevalence of PJP among AIDS/HIV patients ranged from 10 to $46.7 \%$ [104-106], while in Iran, PJP ranged from 4.5 to 39.3\% [107-109]. Regarding the Arabian Peninsula region, PJP occurring in 9 episodes among primary immunodeficiency disorder patients in Kuwait [110] was found in $5.1 \%$ of 


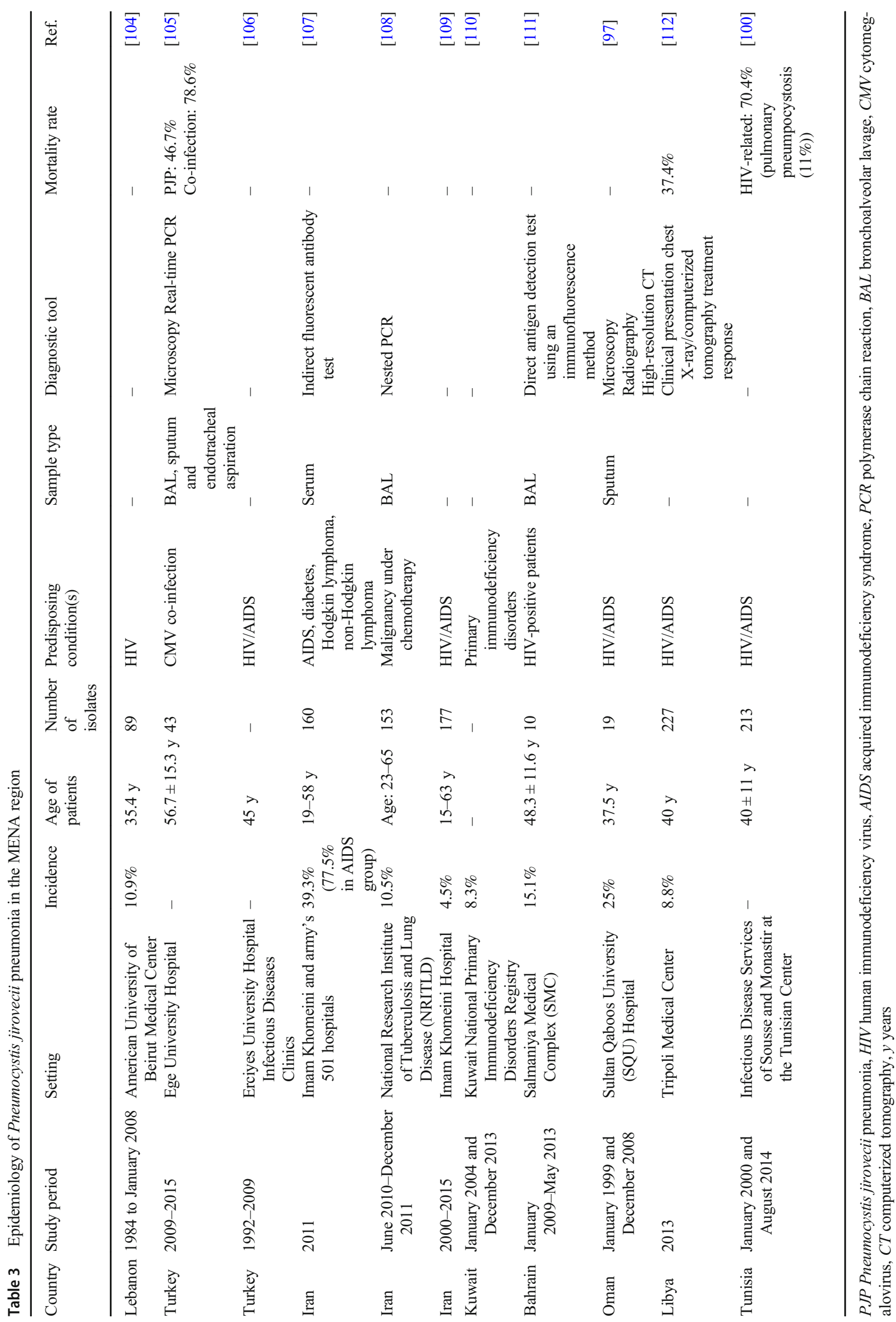


total HIV-infected patients in Bahrain [111], while accounted for $25 \%$ of opportunistic infections in HIV/AIDS patients in Oman with no mortality reported due to this infection [97]. Concerning North Africa, a retrospective analysis in 2013 conducted on HIV-related hospitalizations showed that PJP was responsible for $8.8 \%$ respiratory diseases in Libya [112] and accounted for $11.1 \%$ death in HIV-infected patients in Tunisia [100]. Another retrospective study from January 1995 to February 2013 on IFIs reported 4 cases of pneumocystosis among renal transplant recipients [57].

\section{Mucormycosis}

Mucormycosis is an IFI ordinarily seen in individuals with underlying predisposing risk factors including DM and hematological malignancies. Disseminated forms are usually seen in individuals with such risk factors, although rhino-sinusoidal and cutaneous forms may occur in all individuals [113]. Causative agents belong to the subphylum Mucoromycotina. Rhizopus arrhizus is the most common agent causing mucormycosis globally. It is acquired through inhalation of sporangiospores [114]. The global estimates of mucormycosis were around $>10,000$, with an estimate of disseminated mucormycosis around 100,000 [10].

Estimated incidence rates were scarce. The highest estimated rate was in Iran at 9.2 per 100,000 population [17], then in Iraq and Algeria at 0.2 per 100,000 [20, 77]. In Lebanon, an average incidence of 0.83 cases $/ 10,000$ admissions (range $0-2.22$ ) was seen over a 10 -year period in hospitalized patients, in addition to 20\% mucormycosis-related deaths [115]. As for Turkey, 223 cases occurred in hematological malignancies patients and 214 cases in patients with diabetic ketoacidosis [21]. A 17-year assessment indicated $60 \%$ cases of rhino-cerebral and $1.9 \%$ disseminated forms of mucromycosis diagnosed in 151 patients, with $49 \%$ diabetes $39.7 \%$ hematological malignancies comorbidities among them [116]. In Iran, a systematic review indicated that the commonest form was rhino-cerebral (48.9\%) in addition to eight disseminated forms were identified which accounted for $75 \%$ of total mortality [117]. Another 10-year assessment indicated the prevalence of the rhino-cerebral form (95\%) among the total diagnosed mucormycoses [118]. In addition, a case of rhino-orbital mucormycosis caused by Rhizopus oryzae was reported in an acute lymphoblastic leukemia patient [119]. Among children with hematological malignancies, mucoromycetes were responsible for $11.5 \%$ of IFIs and accounted for $53.3 \%$ mortality [120]. An overall incidence rate was estimated at 4.27 per 100 leukemia patients, which decreased from 2001 to 2011 [121].

Concerning the Arabian Peninsula, mucormycosis was estimated to probably being affecting less than 10 patients in Saudi Arabia [19]. A retrospective analysis has reported rhino-cerebral mucormycosis as a cerebral venous thrombosis (CVT) [122]. Gangrenous necrotizing cutaneous mucormycosis in a female neonate who has had injuries on the scalp, abdomen, and back was reported in an ICU in Oman [123].

In North Africa, proven mucormycosis developed in 45 patients in which $90 \%$ of the cases had hematological malignancies in Egypt; in addition to mucormycosis-related complications in 5 cases with disfigurement and perforated hard palate. Mucormycosis-related mortality was 33\% [124]. In December 2010, 3 out of 5 acute leukemia patients due to Rhizomисоr outbreak [125]. Another study during 2010 reported 10 cases of mucormycosis, in which $80 \%$ had pulmonary mucormycosis and only $20 \%$ sinus involvement [126]. As for Tunisia, two patients had died after reporting rhino-cerebral, rhino-orbital, auricular, pulmonary, and cutaneous mucormycosis in one acute leukemia and 3 diabetic patients. The responsible Mucorales were $R$. arrhizus in 3 cases and Lichtheimia corymbifera in 2 cases. [127]. One mucormycosis was reported among 321 renal transplant recipients [57]. Surprisingly, considering the rarity of hemophagocytic lymphohistiocytosis, it was reported to be complicated by sinonasal mucormycosis in a diabetic child [128]. Retrospective analysis of data between 1992 and 2007 included 17 diabetic patients with rhino-orbito-cerebral mucormycosis which resulted in $65 \%$ mortality primarily due to delay in diagnosis and the lack of surgical treatment [129] (Table 4).

\section{Histoplasmosis}

Histoplasma capsulatum, a dimorphic fungus and causative agent of human histoplasmosis, causes respiratory and systemic mycoses in immunocompromised individuals [130]. The global burden of disseminated histoplasmosis is estimated to be 100,000 annual cases [10]. The co-occurrence of histoplasmosis and tuberculosis in advanced HIV poses a diagnostic problem especially in histoplasmosis endemic regions [131]. Histoplasmosis is a known endemic mycoses of North America [132]; however, some reports were made from North Africa. In Morocco, a 39-year-old HIV-infected patient presented sinusitis and cutaneous histoplasmosis [133]. As well, a case of disseminated histoplasmosis caused by $H$. capsulatum was diagnosed in the bone marrow of a 34-year-old HIV-infected woman at Rabta Hospital of Tunis [134].

\section{Concluding remarks}

Despite the limited number of investigations dealing with the epidemiology of IFIs in this geographic area, the currently available data underlines that IFIs are not negligible. There is an urgent need for surveillance and implementation of recommendations and procedures in tertiary care centers in order to stem the morbidity and mortality related to IFIs, particularly among high-risk populations. Furthermore, a regional reference center for invasive mycoses and antifungals at the MENA region, with broad missions, is needed to promote 


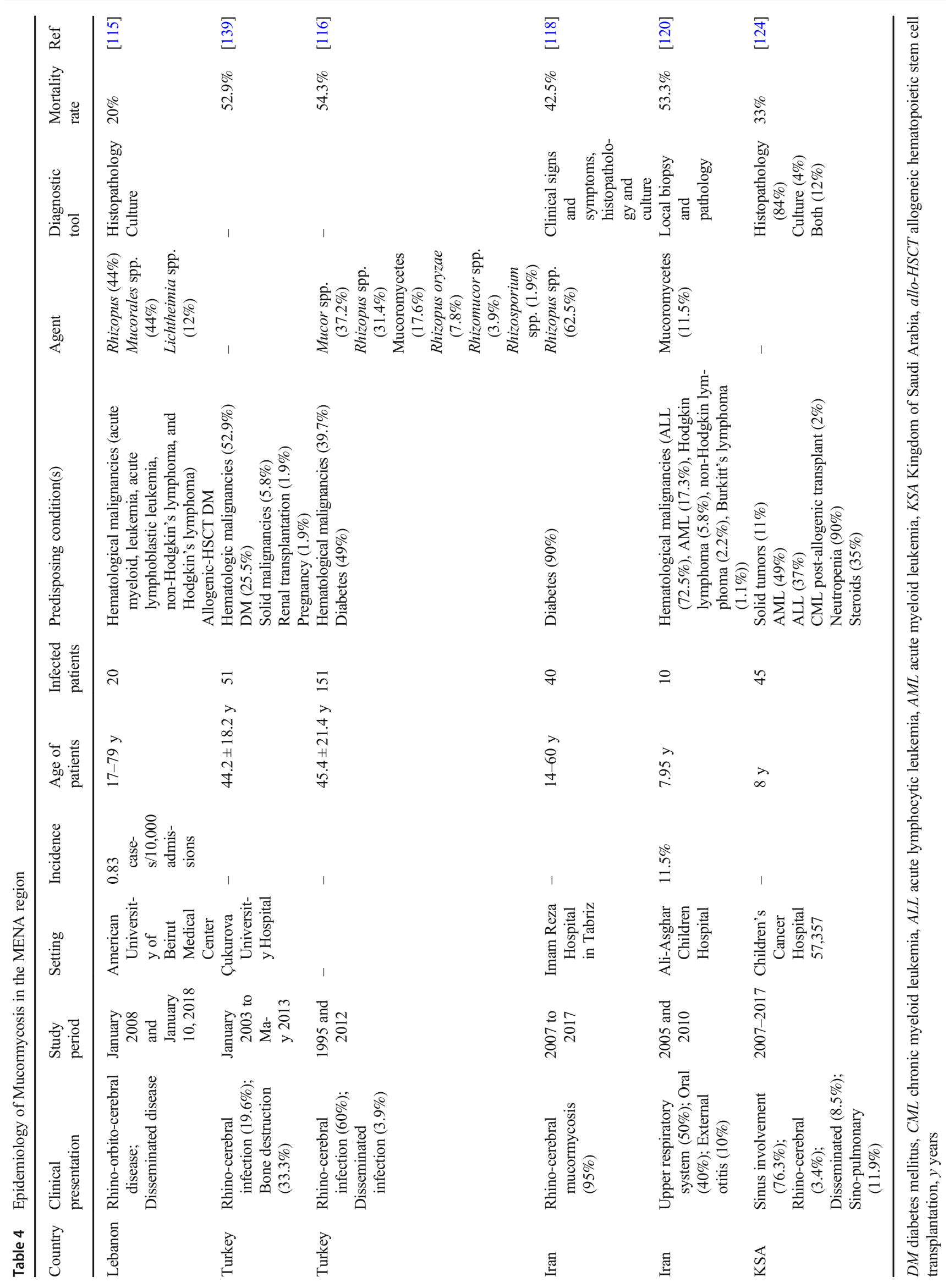


the implementation of antimicrobial stewardship programs in this geographical area.

Acknowledgments The authors would like to thank Basheer Al Bikai for his assistance in the design of the figure.

\section{Compliance with ethical standards}

Conflict of interest The authors declare that they have no conflict of interest.

\section{References}

1. Enoch DA, Yang H, Aliyu SH, Micallef C (2017) The changing epidemiology of invasive fungal infections. Methods Mol Biol 1508:17-65

2. Muskett H, Shahin J, Eyres G, Harvey S, Rowan K, Harrison D (2011) Risk factors for invasive fungal disease in critically ill adult patients: a systematic review. Crit Care 15:R287

3. Tuite NL, Lacey K (2013) Overview of invasive fungal infections. Methods Mol Biol 968:1-23

4. Kabir V, Maertens J, Kuypers D (2019) Fungal infections in solid organ transplantation: an update on diagnosis and treatment. Transplant Rev (Orlando) 33:77-86

5. Cornely OA, Gachot B, Akan H, Bassetti M, Uzun O, Kibbler C, Marchetti O, de Burghgraeve P, Ramadan S, Pylkkanen L, Ameye L, Paesmans M, Donnelly JP, EORTC Infectious Diseases Group (2015) Epidemiology and outcome of fungemia in a cancer cohort of the Infectious Diseases Group (IDG) of the European Organization for Research and Treatment of Cancer (EORTC 65031). Clin Infect Dis 61:324-331

6. Welte T, Len O, Muñoz P, Romani L, Lewis R, Perrella A (2019) Invasive mould infections in solid organ transplant patients: modifiers and indicators of disease and treatment response. Infection. 47:919-927. https://doi.org/10.1007/s15010-019-01360-z

7. Cole DC, Govender NP, Chakrabarti A, Sacarlal J, Denning DW (2017) Improvement of fungal disease identification and management: combined health systems and public health approaches. Lancet Infect Dis 17:e412-e419

8. Batzlaff CM, Limper AH (2017) When to consider the possibility of a fungal infection: an overview of clinical diagnosis and laboratory approaches. Clin Chest Med 38:385-391

9. Delaloye J, Calandra T (2014) Invasive candidiasis as a cause of sepsis in the critically ill patient. Virulence 5:161-169

10. Bongomin F, Gago S, Oladele RO, Denning DW (2017) Global and multi-national prevalence of fungal diseases-estimate precision. J Fungi (Basel) 3. https://doi.org/10.3390/jof3040057

11. Guinea J (2014) Global trends in the distribution of Candida species causing candidemia. Clin Microbiol Infect 20(Suppl 6):5-10

12. Miceli MH, Díaz JA, Lee SA (2011) Emerging opportunistic yeast infections. Lancet Infect Dis 11:142-151

13. Sears D, Schwartz BS (2017) Candida auris: an emerging multidrug-resistant pathogen. Int J Infect Dis 63:95-98

14. Coste AT, Imbert C, Hennequin C (2019) Candida auris, an emerging and disturbing yeast. J Mycol Med 29:105-106

15. Bidaud AL, Chowdhary A, Dannaoui E (2018) Candida auris: an emerging drug resistant yeast - a mini-review. J Mycol Med 28: $568-573$

16. Taj-Aldeen SJ, Chandra P, Denning DW (2015) Burden of fungal infections in Qatar. Mycoses 58(Suppl 5):51-57

17. Hedayati M, Tagizadeh M, Charati J, Denning D (2013) Burden of serious fungal infection in Iran. J Infect Dev Ctries 12:910-918
18. Zaki SM, Denning DW (2017) Serious fungal infections in Egypt. Eur J Clin Microbiol Infect Dis 36:971-974

19. Albarrag AM, Al-Abdely H, Abu Khalid NF, Denning DW. Burden of serious fungal infections in Saudi Arabia

20. Chekiri-Talbi M, Denning DW (2017) Burden of fungal infections in Algeria. Eur J Clin Microbiol Infect Dis 36:999-1004

21. Hilmioğlu-Polat S, Seyedmousavi S, Ilkit M, Hedayati MT, Inci R, Tumbay E, Denning DW (2019) Estimated burden of serious human fungal diseases in Turkey. Mycoses 62:22-31

22. Wadi J, Denning DW (2018) Burden of serious fungal infections in Jordan. J Fungi (Basel). 4. https://doi.org/10.3390/jof4010015

23. Dufresne SF, Cole DC, Denning DW, Sheppard DC (2017) Serious fungal infections in Canada. Eur J Clin Microbiol Infect Dis 36:987-992

24. Giacomazzi J, Baethgen L, Carneiro LC, Millington MA, Denning DW, Colombo AL, Pasqualotto AC, Association With The LIFE Program (2016) The burden of serious human fungal infections in Brazil. Mycoses 59:145-150

25. Corzo-León DE, Armstrong-James D, Denning DW (2015) Burden of serious fungal infections in Mexico. Mycoses 58(Suppl 5):34-44

26. Klimko N, Kozlova Y, Khostelidi S, Shadrivova O, Borzova Y, Burygina E, Vasilieva N, Denning DW (2015) The burden of serious fungal diseases in Russia. Mycoses 58(Suppl 5):58-62

27. Mareş M, Moroti-Constantinescu VR, Denning DW (2018) The burden of fungal diseases in Romania. J Fungi (Basel). 4. https:// doi.org/10.3390/jof4010031

28. Jabeen K, Farooqi J, Mirza S, Denning D, Zafar A (2017) Serious fungal infections in Pakistan. Eur J Clin Microbiol Infect Dis 36: 949-956

29. Zhu LP, Wu JQ, Denning DW (2013) Burden of serious fungal infections in China

30. Ruhnke M, Groll AH, Mayser P, Ullmann AJ, Mendling W, Hof $\mathrm{H}$, Denning DW, University of Manchester in association with the LIFE program (2015) Estimated burden of fungal infections in Germany. Mycoses 58(Suppl 5):22-28

31. Pegorie M, Denning DW, Welfare W (2017) Estimating the burden of invasive and serious fungal disease in the United Kingdom. J Inf Secur 74:60-71

32. Schwartz I, Denning D (2019) The estimated burden of fungal diseases in South Africa. Journal of Infection and Public Health $12: 124$

33. Tufa TB, Denning DW (2019) The burden of fungal infections in Ethiopia. J Fungi (Basel). 5. https://doi.org/10.3390/jof5040109

34. Badiane AS, Ndiaye D, Denning DW (2015) Burden of fungal infections in Senegal. Mycoses 58(Suppl 5):63-69

35. Gamaletsou MN, Drogari-Apiranthitou M, Denning DW, Sipsas NV (2016) An estimate of the burden of serious fungal diseases in Greece. Eur J Clin Microbiol Infect Dis 35:1115-1120

36. Bassetti M, Carnelutti A, Peghin M et al (2018) Estimated burden of fungal infections in Italy. J Inf Secur 76:103-106

37. Gangneux J-P, Bougnoux M-E, Hennequin C, Godet C, Chandenier J, Denning DW, Dupont B, LIFE program, the Société française de mycologie médicale SFMM-study group (2016) An estimation of burden of serious fungal infections in France. J Mycol Med 26:385-390

38. Rodriguez-Tudela JL, Alastruey-Izquierdo A, Gago S, CuencaEstrella M, León C, Miro JM, Nuñez Boluda A, Ruiz Camps I, Sole A, Denning DW (2015) Burden of serious fungal infections in Spain. Clin Microbiol Infect 21:183-189

39. Moghnieh R, Alothman AF, Althaqafi AO, Matar MJ, Alenazi TH, Farahat F, Corman SL, Solem CT, Raghubir N, Macahilig C, Stephens JM (2017) Epidemiology and outcome of invasive fungal infections and methicillin-resistant Staphylococcus aureus (MRSA) pneumonia and complicated skin and soft tissue 
infections (cSSTI) in Lebanon and Saudi Arabia. J Infect Public Health 10:849-854

40. Ababneh M, Abu-Bdair OA, Mhaidat N, Almomani BA (2017) Characteristics and clinical outcomes of patients with Candida bloodstream infections in a tertiary care hospital in Jordan. J Infect Dev Ctries 11:861-867

41. Kazak E, Akın H, Ener B, Sığırlı D, Özkan Ö, Gürcüoğlu E, Y1lmaz E, Çelebi S, Akçağlar S, Akalın H (2014) An investigation of Candida species isolated from blood cultures during 17 years in a university hospital. Mycoses 57:623-629

42. Sutcu M, Salman N, Akturk H, Dalgic N, Turel O, Kuzdan C, Kadayifci EK, Sener D, Karbuz A, Erturan Z, Somer A (2016) Epidemiologic and microbiologic evaluation of nosocomial infections associated with Candida spp in children: a multicenter study from Istanbul, Turkey. Am J Infect Control 44:1139-1143

43. Yeșilkaya A, Azap Ö, Aydın M, Akçil Ok M (2017) Epidemiology, species distribution, clinical characteristics and mortality of candidaemia in a tertiary care university hospital in Turkey, 2007-2014. Mycoses 60:433-439

44. Tukenmez Tigen E, Bilgin H, Perk Gurun H, Dogru A, Ozben B, Cerikcioglu N, Korten V (2017) Risk factors, characteristics, and outcomes of candidemia in an adult intensive care unit in Turkey. Am J Infect Control 45:e61-e63

45. Celebi S, Hacimustafaoglu M, Koksal N, Ozkan H, Cetinkaya M, Ener B (2012) Neonatal candidiasis: results of an 8 year study. Pediatr Int 54:341-349

46. Charsizadeh A, Mirhendi H, Nikmanesh B, Eshaghi H, Makimura $\mathrm{K}$ (2018) Microbial epidemiology of candidaemia in neonatal and paediatric intensive care units at the Children's Medical Center, Tehran. Mycoses 61:22-29

47. Vaezi A, Fakhim H, Khodavaisy S, Alizadeh A, Nazeri M, Soleimani A, Boekhout T, Badali H (2017) Epidemiological and mycological characteristics of candidemia in Iran: a systematic review and meta-analysis. J Mycol Med 27:146-152

48. Omrani AS, Makkawy EA, Baig K, Baredhwan AA, Almuthree SA, Elkhizzi NA, Albarrak AM (2014) Ten-year review of invasive Candida infections in a tertiary care center in Saudi Arabia. Saudi Med J 35:821-826

49. Al-Dorzi HM, Sakkijha H, Khan R, Aldabbagh T, Toledo A, Ntinika P, Al Johani SM, Arabi YM (2018) Invasive candidiasis in critically ill patients: a prospective cohort study in two tertiary care centers. J Intensive Care Med 885066618767835

50. Almooosa Z, Ahmed GY, Omran A, AlSarheed A, Alturki A, Alaqeel A, Alshehri M, Alfawaz T, AlShahrani D (2017) Invasive candidiasis in pediatric patients at kIng Fahad Medical City in Central Saudi Arabia. A 5-year retrospective study. Saudi Med J 38:1118-1124

51. Al Thaqafi AHO, Farahat FM, Al Harbi MI, Al Amri AFW, Perfect JR (2014) Predictors and outcomes of Candida bloodstream infection: eight-year surveillance, western Saudi Arabia. Int J Infect Dis 21:5-9

52. Alobaid K, Khan Z (2019) Epidemiologic characteristics of adult candidemic patients in a secondary hospital in Kuwait: a retrospective study. J Mycol Med 29:35-38

53. Taj-Aldeen SJ, Kolecka A, Boesten R, Alolaqi A, Almaslamani M, Chandra P, Meis JF, Boekhout T (2014) Epidemiology of candidemia in Qatar, the Middle East: performance of MALDITOF MS for the identification of Candida species, species distribution, outcome, and susceptibility pattern. Infection 42:393-404

54. Hegazi M, Abdelkader A, Zaki M, El-Deek B (2014) Characteristics and risk factors of candidemia in pediatric intensive care unit of a tertiary care children's hospital in Egypt. J Infect Dev Ctries 8:624-634

55. Saghrouni F, Bougmiza I, Ben Abdeljelil J, Yacoub A, Khammari I, Fathallah A, Mtiraoui A, Ben Saïd M (2011) Epidemiological trends in invasive candidiasis: results from a 15-year study in Sousse Region, Tunisia. J Mycol Med 21:123-129

56. Ben Abdeljelil J, Saghrouni F, Nouri S, Geith S, Khammari I, Fathallah A, Sboui H, Ben Saïd M (2012) Neonatal invasive candidiasis in Tunisian hospital: incidence, risk factors, distribution of species and antifungal susceptibility. Mycoses 55:493-500

57. Trabelsi H, Néji S, Sellami H, Yaich S, Cheikhrouhou F, Guidara R, Charffedine K, Makni F, Hachicha J, Ayadi A (2013) Invasive fungal infections in renal transplant recipients: about 11 cases. J Mycol Med 23:255-260

58. Cherkaoui S, Lamchahab M, Samira H, Zerouali K, Madani A, Benchekroun S, Quessar A (2014) Healthcare-associated infections in a paediatric haematology/oncology unit in Morocco. Sante Publique 26:199-204

59. Rosenthal VD, Jarvis WR, Jamulitrat S, Silva CP, Ramachandran B, Dueñas L, Gurskis V, Ersoz G, Novales MG, Khader IA, Ammar K, Guzmán NB, Navoa-Ng JA, Seliem ZS, Espinoza TA, Meng CY, Jayatilleke K, International Nosocomial Infection Control Members (2012) Socioeconomic impact on device-associated infections in pediatric intensive care units of 16 limited-resource countries: international Nosocomial Infection Control Consortium findings. Pediatr Crit Care Med 13:399-406

60. Tadmouri GO, Mandil A, Rashidian A (2019) Biomedical and health research geography in the Eastern Mediterranean Region. East Mediterr Health J 25:728-743

61. Khan Z, Ahmad S, Al-Sweih N et al (2019) Changing trends in epidemiology and antifungal susceptibility patterns of six bloodstream Candida species isolates over a 12-year period in Kuwait. PLoS One 14:e0216250

62. Ghazi S, Rafei R, Osman M, El Safadi D, Mallat H, Papon N, Dabboussi F, Bouchara J-P, Hamze M (2019) The epidemiology of Candida species in the Middle East and North Africa. J Mycol Med 29:245-252

63. Alatoom A, Sartawi M, Lawlor K, AbdelWareth L, Thomsen J, Nusair A, Mirza I (2018) Persistent candidemia despite appropriate fungal therapy: first case of Candida auris from the United Arab Emirates. Int J Infect Dis 70:36-37

64. Khan Z, Ahmad S, Al-Sweih N, Joseph L, Alfouzan W, Asadzadeh M (2018) Increasing prevalence, molecular characterization and antifungal drug susceptibility of serial Candida auris isolates in Kuwait. PLoS One 13:e0195743

65. Khan Z, Ahmad S, Benwan K, Purohit P, al-Obaid I, Bafna R, Emara M, Mokaddas E, Abdullah AA, al-Obaid K, Joseph L (2018) Invasive Candida auris infections in Kuwait hospitals: epidemiology, antifungal treatment and outcome. Infection 46: 641-650

66. Abdalhamid B, Almaghrabi R, Althawadi S, Omrani A (2018) First report of Candida auris infections from Saudi Arabia. J Infect Public Health 11:598-599

67. Elsawy A, Alquthami K, Alkhutani N, Marwan D, Abbas A (2019) The second confirmed case of Candida auris from Saudi Arabia. J Infect Public Health 12:907-908. https://doi.org/10. 1016/j.jiph.2019.07.011

68. Ahmad S, Khan Z, Al-Sweih N, Alfouzan W, Joseph L (2019) Candida auris in various hospitals across Kuwait and their susceptibility and molecular basis of resistance to antifungal drugs. Mycoses. 63:104-112. https://doi.org/10.1111/myc.13022

69. Lee WG, Shin JH, Uh Y, Kang MG, Kim SH, Park KH, Jang H-C (2011) First three reported cases of nosocomial fungemia caused by Candida auris. J Clin Microbiol 49:3139-3142

70. Kathuria S, Singh PK, Sharma C, Prakash A, Masih A, Kumar A, Meis JF, Chowdhary A (2015) Multidrug-resistant Candida auris misidentified as Candida haemulonii: characterization by matrixassisted laser desorption ionization-time of flight mass spectrometry and DNA sequencing and its antifungal susceptibility profile 
variability by Vitek 2, CLSI broth microdilution, and Etest method. J Clin Microbiol 53:1823-1830

71. Morales-López SE, Parra-Giraldo CM, Ceballos-Garzón A, Martínez HP, Rodríguez GJ, Álvarez-Moreno CA, Rodríguez JY (2017) Invasive infections with multidrug-resistant yeast Candida auris, Colombia. Emerging Infect Dis 23:162-164

72. (2019) Candida auris: a drug-resistant germ that spreads in healthcare facilities | Candida auris | Fungal Diseases | CDC. https://www.cdc.gov/fungal/candida-auris/c-auris-drug-resistant. html. Accessed 6 Mar 2020

73. Taccone FS, Van den Abeele A-M, Bulpa P et al (2015) Epidemiology of invasive aspergillosis in critically ill patients: clinical presentation, underlying conditions, and outcomes. Crit Care 19:7

74. Zilberberg MD, Nathanson BH, Harrington R, Spalding JR, Shorr AF (2018) Epidemiology and outcomes of hospitalizations with invasive aspergillosis in the United States, 2009-2013. Clin Infect Dis 67:727-735

75. Barnes PD, Marr KA (2006) Aspergillosis: spectrum of disease, diagnosis, and treatment. Infect Dis Clin N Am 20(545-561):vi

76. Sugui JA, Kwon-Chung KJ, Juvvadi PR, Latgé J-P, Steinbach WJ (2014) Aspergillus fumigatus and related species. Cold Spring Harb Perspect Med 5:a019786

77. Karzan MA, Ismael HM, Shekhany K, Al-Attraqhchi AAF, Abdullah S, Aldabbagh R, Denning DW (2014) Burden of serious fungal infection in Iraq

78. Alsalman J, Zaid T, Makhlooq M, Madan M, Mohamed Z, Alarayedh A, Ghareeb A, Kamal N (2017) A retrospective study of the epidemiology and clinical manifestation of invasive aspergillosis in a major tertiary care hospital in Bahrain. J Infect Public Health 10:49-58

79. Gheith S, Ranque S, Bannour W, Ben Youssef Y, Khelif A, Ben Said M, Njah M, Saghrouni F (2015) Hospital environment fungal contamination and aspergillosis risk in acute leukaemia patients in Sousse (Tunisia). Mycoses 58:337-342

80. Gheith S, Saghrouni F, Bannour W, Ben Youssef Y, Khelif A, Normand A-C, Ben Said M, Piarroux R, Njah M, Ranque S (2014) Characteristics of invasive aspergillosis in neutropenic haematology patients (Sousse, Tunisia). Mycopathologia 177: 281-289

81. Hadrich I, Makni F, Sellami H, Cheikhrouhou F, Sellami A, Bouaziz H, Hdiji S, Elloumi M, Ayadi A (2010) Invasive aspergillosis: epidemiology and environmental study in haematology patients (Sfax, Tunisia). Mycoses 53:443-447

82. Saghrouni F, Ben Youssef Y, Gheith S, Bouabid Z, Ben Abdeljelil J, Khammari I, Fathallah A, Khlif A, Ben Saïd M (2011) Twentynine cases of invasive aspergillosis in neutropenic patients. Med Mal Infect 41:657-662

83. Zanganeh E, Zarrinfar H, Rezaeetalab F, Fata A, Tohidi M, Najafzadeh MJ, Alizadeh M, Seyedmousavi S (2018) Predominance of non-fumigatus Aspergillus species among patients suspected to pulmonary aspergillosis in a tropical and subtropical region of the Middle East. Microb Pathog 116:296-300

84. Gheith S, Saghrouni F, Bannour W, Ben Youssef Y, Khelif A, Normand A-C, Piarroux R, Ben Said M, Njah M, Ranque S (2014) In vitro susceptibility to amphotericin B, itraconazole, voriconazole, posaconazole and caspofungin of Aspergillus spp. isolated from patients with haematological malignancies in Tunisia. Springerplus 3:19

85. Loyse A, Thangaraj H, Easterbrook P, Ford N, Roy M, Chiller T, Govender N, Harrison TS, Bicanic T (2013) Cryptococcal meningitis: improving access to essential antifungal medicines in resource-poor countries. Lancet Infect Dis 13:629-637

86. Galanis E, MacDougall L, Kidd S, Morshed M (2010) Epidemiology of Cryptococcus gattii, British Columbia, Canada, 1999-2007. Emerg Infect Dis 16:251-257
87. Lin X, Heitman J (2006) The biology of the Cryptococcus neoformans species complex. Annu Rev Microbiol 60:69-105

88. Rajasingham R, Smith RM, Park BJ, Jarvis JN, Govender NP, Chiller TM, Denning DW, Loyse A, Boulware DR (2017) Global burden of disease of HIV-associated cryptococcal meningitis: an updated analysis. Lancet Infect Dis 17:873-881

89. Taşbakan MS, Yamazhan T, Aydemir S, Bacakoğlu F (2010) A case of ventilator-associated pneumonia caused by Cupriavidus pauculus. Mikrobiyol Bul 44:127-131

90. Hunter-Ellul L, Schepp ED, Lea A, Wilkerson MG (2014) A rare case of Cryptococcus luteolus-related tenosynovitis. Infection 42:771-774

91. Badali H, Alian S, Fakhim H, Falahatinejad M, Moradi A, Mohammad Davoudi M, Hagen F, Meis JF (2015) Cryptococcal meningitis due to Cryptococcus neoformans genotype AFLP1/ VNI in Iran: a review of the literature. Mycoses 58:689-693

92. Hajiabdolbaghi M, Kalantari S, Jamshidi-Makiani M, Shojaei E, Abbasian L, Rasoulinezhad M, Tayeri K (2017) Prevalence of cryptococcal antigen positivity among HIV infected patient with CD4 cell count less than 100 of Imam Khomeini Hospital, Tehran, Iran. Iran J Microbiol 9:119-121

93. Agha Kuchak Afshari S, Shokohi T, Aghili R, Badali H (2012) Epidemiology and molecular characterization of Cryptococcus neoformans isolated from pigeon excreta in Mazandaran Province, Northern Iran. J Mycol Med 22:160-166

94. Ghaderi Z, Eidi S, Razmyar J (2019) High prevalence of Cryptococcus neoformans and isolation of other opportunistic fungi from pigeon (Columba livia) droppings in Northeast Iran. J Avian Med Surg 33:335-339

95. Al-Rasheed SA, Al-Fawaz IM (1990) Cryptococcal meningitis in a child with systemic lupus erythematosus. Ann Trop Paediatr 10:323-326

96. Sa'adah MA, Araj GF, Diab SM, Nazzal M (1995) Cryptococcal meningitis and confusional psychosis. A case report and literature review. Trop Geogr Med 47:224-226

97. Balkhair AA, Al-Muharrmi ZK, Ganguly S, Al-Jabri AA (2012) Spectrum of AIDS defining opportunistic infections in a series of 77 hospitalised HIV-infected Omani patients. Sultan Qaboos Univ Med J 12:442-448

98. Ellabib MS, Krema ZA, Allafi AA, Cogliati M (2017) First report of two cases of cryptococcosis in Tripoli, Libya, infected with Cryptococcus neoformans isolates present in the urban area. $\mathrm{J}$ Mycol Med 27:421-424

99. El Fane M, Sodqi M, Lamdini H, Marih L, Lahsen AO, Chakib A, El Filali KM (2018) Central neurological diagnosis in patients infected with HIV in the infectious diseases unit of University Hospital of Casablanca, Morocco. Bull Soc Pathol Exot 111:24-30

100. Chelli J, Bellazreg F, Aouem A, Hattab Z, Mesmia H, Lasfar NB, Hachfi W, Masmoudi T, Chakroun M, Letaief A (2016) Causes of death in patients with HIV infection in two Tunisian medical centers. Pan Afr Med J 25:105

101. Ma L, Cissé OH, Kovacs JA (2018) A molecular window into the biology and epidemiology of Pneumocystis spp. Clin Microbiol Rev 31. https://doi.org/10.1128/CMR.00009-18

102. Icenhour CR, Rebholz SL, Collins MS, Cushion MT (2002) Early acquisition of Pneumocystis carinii in neonatal rats as evidenced by PCR and oral swabs. Eukaryot Cell 1:414-419

103. Patterson L, Coyle P, Curran T, Verlander NQ, Johnston J (2017) Changing epidemiology of Pneumocystis pneumonia, Northern Ireland, UK and implications for prevention, 1 July 2011-31 July 2012. J Med Microbiol 66:1650-1655

104. Naba MR, Kanafani ZA, Awar GN, Kanj SS (2010) Profile of opportunistic infections in HIV-infected patients at a tertiary care center in Lebanon. J Infect Public Health 3:130-133

105. Korkmaz Ekren P, Töreyin ZN, Nahid P, Doskaya M, Caner A, Turgay N, Zeytinoglu A, Toz S, Bacakoglu F, Guruz Y, Erensoy S (2018) The association between Cytomegalovirus co-infection 
with Pneumocystis pneumonia and mortality in immunocompromised non-HIV patients. Clin Respir J 12:2590-2597

106. Alp E, Bozkurt I, Doğanay M (2011) Epidemiological and clinical characteristics of HIV/AIDS patients followed-up in Cappadocia region: 18 years experience. Mikrobiyol Bul 45:125-136

107. Homayouni MM, Behniafar H, Mehbod ASA, MohammadSadeghi M-J, Maleki B (2017) Prevalence of Pneumocystis jirovecii among immunocompromised patients in hospitals of Tehran City, Iran. J Parasit Dis 41:850-853

108. Sheikholeslami MF, Sadraei J, Farnia P, Forozandeh M, Emadi Kochak H, Tabarsi P, Nadji SA, Pirestani M, Masjedi MR, Velayati A (2013) Colonization of Pneumocystis jirovecii in chronic obstructive pulmonary disease (COPD) patients and the rate of Pneumocystis pneumonia in Iranian non-HIV(+) immunocompromised patients. Iran J Microbiol 5:411-417

109. Alinaghi SAS, Vaghari B, Roham M, Badie BM, Jam S, Foroughi M, Djavid GE, Hajiabdolbaghi M, Hosseini M, Mohraz M, McFarland W (2011) Respiratory complications in Iranian hospitalized patients with HIV/AIDS. Tanaffos 10:49-54

110. Owayed A, Al-Herz W (2016) Sinopulmonary complications in subjects with primary immunodeficiency. Respir Care 61:1067-1072

111. Saeed NK, Farid E, Jamsheer AE (2015) Prevalence of opportunistic infections in HIV-positive patients in Bahrain: a four-year review (2009-2013). J Infect Dev Ctries 9:60-69

112. Shalaka NS, Garred NA, Zeglam HT, Awasi SA, Abukathir LA, Altagdi ME, Rayes AA (2015) Clinical profile and factors associated with mortality in hospitalized patients with HIV/AIDS: a retrospective analysis from Tripoli Medical Centre, Libya, 2013. East Mediterr Health J 21:635-646

113. Krishnappa D, Naganur S, Palanisamy D, Kasinadhuni G (2019) Cardiac mucormycosis: a case report. Eur Heart J Case Rep 3. https://doi.org/10.1093/ehjcr/ytz130

114. Richardson M (2009) The ecology of the Zygomycetes and its impact on environmental exposure. Clin Microbiol Infect 15(Suppl 5):2-9

115. El Zein S, El-Cheikh J, El Zakhem A, Ibrahim D, Bazarbachi A, Kanj SS (2018) Mucormycosis in hospitalized patients at a tertiary care center in Lebanon: a case series. Infection 46:811-821

116. Zeka AN, Taşbakan M, Pullukçu H, Sipahi OR, Yamazhan T, Arda B (2013) Evaluation of zygomycosis cases by pooled analysis method reported from Turkey. Mikrobiyol Bul 47:708-716

117. Vaezi A, Moazeni M, Rahimi MT, de Hoog S, Badali H (2016) Mucormycosis in Iran: a systematic review. Mycoses 59:402-415

118. Nezafati S, Kazemi A, Asgari K, Bahrami A, Naghili B, Yazdani J (2018) Rhinocerebral mucormycosis, risk factors and the type of oral manifestations in patients referred to a University Hospital in Tabriz, Iran 2007-2017. Mycoses 61:764-769

119. Gumral R, Yildizoglu U, Saracli MA, Kaptan K, Tosun F, Yildiran ST (2011) A case of rhinoorbital mucormycosis in a leukemic patient with a literature review from Turkey. Mycopathologia 172:397-405

120. Ansari S, Shirzadi E, Elahi M (2015) The prevalence of fungal infections in children with hematologic malignancy in Ali-Asghar Children Hospital between 2005 and 2010. Iran J Ped Hematol Oncol 5:1-10

121. Sarvestani SA, Pishdad G, Bolandparvaz S (2014) Epidemiology and clinical characteristics of mucormycosis in patients with leukemia; a 21-year experience from Southern Iran. Bull Emerg Trauma 2:38-43

122. Kajtazi NI, Zimmerman VA, Arulneyam JC, Al-Shami SY, AlSenani FM (2009) Cerebral venous thrombosis in Saudi Arabia. Clinical variables, response to treatment, and outcome. Neurosciences (Riyadh) 14:349-354

123. Sawardekar KP (2018) Gangrenous necrotizing cutaneous mucormycosis in an immunocompetent neonate: a case report from Oman. J Trop Pediatr 64:548-552
124. Khedr R, Madney Y, Ahmed N, El-Mahallawy H, Yousef A, Taha H, Hassanain O, Taha G, Hafez H (2019) Overview and outcome of mucormycosis among children with cancer; Report From The Children's Cancer Hospital Egypt Mycoses https://doi.org/10. 1111/myc.12915, 62, 984, 989

125. El-Mahallawy HA, Khedr R, Taha H, Shalaby L, Mostafa A (2016) Investigation and Management of a Rhizomucor Outbreak in a Pediatric Cancer Hospital in Egypt. Pediatr Blood Cancer 63:171-173

126. Zaki SM, Elkholy IM, Elkady NA, Abdel-Ghany K (2014) Mucormycosis in Cairo, Egypt: review of 10 reported cases. Med Mycol 52:73-80

127. Bellazreg F, Hattab Z, Meksi S, Mansouri S, Hachfi W, Kaabia N, Ben Said M, Letaief A (2015) Outcome of mucormycosis after treatment: report of five cases. New Microbes New Infect 6:49-52

128. Bahloul M, Tounsi A, Chaari A, Ben Aljia N, Ammar R, Chelly H, Bouaziz M (2012) Rhinocerebral mucormycosis complicated by hemophagocytic lymphohistiocytosis: case report from Tunisia. Med Sante Trop 22:210-212

129. Anane S, Kaouech E, Belhadj S, Ammari L, Abdelmalek R, Ben Chaabane T, Ben Lakhal S, Cherif A, Ammamou M, Ben Fadhel K, Kallel K, Chaker E (2009) Rhino-orbito-cerebral mucormycosis in the diabetic: a better known pathology in Tunisia. Ann Biol Clin (Paris) 67:325-332

130. Bennett JE, Dolin R, Blaser MJ (2014) Mandell, Douglas, and Bennett's principles and practice of infectious diseases, 8th ed.

131. Caceres DH, Valdes A (2019) Histoplasmosis and tuberculosis cooccurrence in people with advanced HIV. J Fungi (Basel). 5. https://doi.org/10.3390/jof5030073

132. Armstrong PA, Jackson BR, Haselow D, Fields V, Ireland M, Austin C, Signs K, Fialkowski V, Patel R, Ellis P, Iwen PC, Pedati C, Gibbons-Burgener S, Anderson J, Dobbs T, Davidson S, McIntyre M, Warren K, Midla J, Luong N, Benedict K (2018) Multistate epidemiology of histoplasmosis, United States, 20112014. Emerging Infect Dis 24:425-431

133. Elansari R, Abada R, Rouadi S, Roubal M, Mahtar M (2016) Histoplasma capsulatum sinusitis: possible way of revelation to the disseminated form of histoplasmosis in HIV patients: case report and literature review. Int J Surg Case Rep 24:97-100

134. Fakhfakh N, Abdelmlak R, Aissa S, Kallel A, Boudawara Y, Bel Hadj S, Ben Romdhane N, Touiri Ben Aissa H, Kallel K (2018) Disseminated histoplasmosis diagnosed in the bone marrow of an HIV-infected patient: first case imported in Tunisia. J Mycol Med 28:211-214

135. Ulu Kilic A, Alp E, Cevahir F, Ture Z, Yozgat N (2017) Epidemiology and cost implications of candidemia, a 6-year analysis from a developing country. Mycoses 60:198-203

136. Birinci A, Cayci YT, Bilgin K, Gunaydin M, Acuner C, Esen S (2011) Comparison of nosocomial candidemia of pediatric and adult cases in 2-years period at a Turkish university hospital. Eurasian J Med 43:87-91

137. Yousefi M, Yadegarynia D, Lotfali E, Arab-Mazar Z, Ghajari A, Fatemi A (2018) Candidemia in febrile neutropenic patients; a brief report. Emerg (Tehran) 6:e39

138. Razzaghi R, Momen-Heravi M, Erami M, Nazeri M (2016) Candidemia in patients with prolonged fever in Kashan, Iran. Curr Med Mycol 2:20-26

139. Kömür S, İnal AS, Kurtaran B, Ulu A, Uğuz A, Aksu HSZ, Taşova Y (2016) Mucormycosis: a 10-year experience at a tertiary care center in Turkey. Turk J Med Sci 46:58-62

Publisher's note Springer Nature remains neutral with regard to jurisdictional claims in published maps and institutional affiliations. 